\title{
Integral Treatment of Systemic Lupus Erythematosus
}

\author{
Raquel Ramírez Parrondo \\ Clínica, Universidad de Navarra, Madrid \\ Spain
}

\section{Introduction}

Systemic lupus erythematosus (SLE) is a chronic inflammatory autoimmune disease of unknown etiology. The prevalence of SLE is worldwide from 4 to 250 per 100,000. Statistics demonstrate that lupus is somewhat more frequent in Africans, Americans and people of Chinese and Japanese descent. It is a disease with predominance of the female sex, the ratio among SLE sufferers is about 9:1.

It is often discovered in their childbearing years. It affects heterogeneity multiple organs of the body and presents aberrant immunological findings and especially the presence of antinuclear antibodies. The clinical course and prognosis is unpredictable and may be characterized by periods of remissions and chronic or acute relapses. The mortality rate among patients with SLE is at least three times that of the general population. (Aberer, 2010; Ng \& Chan, 2007; Ramírez, 2007)

\section{Etiopathogenesis}

The etiopathogenesis that causes lupus is not known. Interactions between susceptibility genes and environmental factors result in abnormal immune responses. The antigens, autoantibodies, and immune complexes persist for prolonged periods of time, allowing inflammation and contribute to irreversible tissue damage developing the disease.

The SLE is a multigenic disease. In most genetically susceptible individuals, if enough variations accumulate multiple genes they contribute to abnormal immune responses and disease results. Some genes influence clinical manifestations of disease in various ethnic groups. (Javierre \& Richardson, 2011; Koike, 2011)

The SLE is more frequent in female sex. The females make higher antibody responses than the males. The estrogens favour a prolonged immune response increasing the risk of developing SLE.

Several environmental stimuli may influence in the development of the SLE. Exposure to ultraviolet light causes skin injures in approximately $70 \%$ of SLE patients. Some infections, for example Epstein-Barr virus (EBV), induce abnormal immune response. Occasionally, some drugs stimulate the immune system and can induce SLE. The extreme stress may trigger the illness. (Ng \& Chan, 2007; Niller et al,2011; Nowicka-Sauer, 2007; Ramírez, 2007) 


\section{Clinical manifestations}

The illness impacts in the patients with SLE, in three aspects: physical, psychological and social. (Ng \& Chan, 2007; Ramírez, 2007)

\subsection{Physical manifestations}

The physical manifestations varies between different patients, and in a single patient the disease activity varies presenting exacerbations interspersed with periods of relative quiescence. SLE may involve one or several organ systems, but it is not usual for all systems to be affected simultaneously, and the severity varies from mild and intermittent to fulminant.

The general symptoms, particularly fatigue and fever, are present most of the time. The myalgias and or arthralgias are common. Most patients have intermittent polyarthritis most frequently in hands, wrists, and knees. The exercise capacity and muscular strength are reduced in these people.

Lupus dermatitis can be "butterfly" rash on the face, discoid lupus, photosensitivity, systemic rash, urticaria. About one-third of the patients have small, painful ulcerations on the oral or nasal mucosa.

The nephropathy in SLE varies from mild proteinuria and microscopical hematuria to endstage renal failure.

The neuropsychiatric symptoms can be caused by a diffuse process or vascular occlusive disease. The manifestations of diffuse CNS lupus are cognitive dysfunction, depression and headache, myelopathy, peripheral neuropathy, seizures and psychosis. Many patients get a thromboembolic or haemorrhagic complication of the brain.

The pulmonary manifestations of SLE are pleuritis, acute pneumonitis and chronic fibrotising alveolitis.

The cardiac manifestations are pericarditis, myocarditis, fibrinous endocarditis of LibmanSacks, heart failure, arrhythmia and myocardial infarctions.

The hematologic manifestations of SLE are anemia, usually normochromic normocytic, hemolysis, leukopenia lymphopenia, and thrombocytopenia.

The gastrointestinal manifestations are nausea, sometimes with vomiting, diarrhea or diffuse abdominal pain caused by peritonitis, intestinal vasculitis.

The ocular manifestations are sicca syndrome, nonspecific conjunctivitis, retinal vasculitis and optic neuritis.

Women with SLE have more risk of first and second trimester foetal losses and of premature birth. (Nakashima et al, 2011; Ng \& Chan, 2007; Ramírez, 2007)

\subsection{Psychological manifestations}

Many persons with SLE experience high levels of emotional distress. The depression is the most common psychological symptom and the anxiety is another feeling quite frequently experienced.

The links between physical symptoms and psychological wellbeing have been studied in SLE relatively little research.

Studies have revealed that the physical symptoms from SLE affect psychologically to people which suffer.

The skin abnormalities and photosensitivity, disfiguring skin lesions and pleuritic pain are associated with depression, poor self-esteem and poor social functioning. 
The sufferings from greater organ damage, such as the kidneys, experience greater psychological distress.

The disease-related changes to the direct central nervous system can result in depression or anxiety in SLE patients.

Levels of daily stress among patients with SLE are generally higher than those experienced by the general population. Such stress could cause depression and anxiety producing the worsening of physical and mental function in these people. ( $\mathrm{Ng} \&$ Chan, 2007; Ramírez, 2007; Zakeri et al, 2011).

The pharmacology treatment of physical symptoms of SLE can also contribute to feelings of desperation and helplessness among sufferers. The side effects of steroids, such as a "moon face" and weight gain have an additional negative impact on self-esteem. (NavarreteNavarrete et al, 2010; Ng \& Chan, 2007; Chaiamnuay et al, 2007)

The persons with SLE often have worries about their illness, their treatment plans, the level of pain caused by the illness, and the occurrence of the next "flare-up". These people often have a sense of helplessness that the illness is not yet curable even after appropriate treatment is adopted. These worries can be deleterious to their health and self-esteem. The researches associate abnormal illness-related behaviours, helplessness with increased levels of fatigue. (Burgos et al, 2009; Chuang et al, 2010; Ng \& Chan,2007)

Few studies have pointed out that psychiatric symptomatology has been correlated significantly with family and social support. (Ng \& Chan, 2007)

\subsection{Social manifestations}

The uncertainty of SLE affects the social life of these people.

Chronic fatigue and joint pains make it impossible for many with SLE to perform to the level expected by themselves and others. This loss of the ability to meet "normal" standards of performance can be very depressing.

Coupled with the side effects of drug treatment, this condition can lead to feelings of shame, isolation and worthlessness. To avoid the feeling of rejection, many may isolate themselves and refrain from interacting with friends and even family members.

The illness can also have an effect on major life decisions such as career development, wedding and pregnancy plans.

Some may have deep-seated fears of desertion and rejection by spouse and friends.

All these social problems are salient and tend to contribute to emotional and social disturbances (Baker \& Pope, 2009; Ng \& Chan, 2007)

\section{Diagnosis}

The integral diagnosis in the patients with SLE include the aspects: physical, psychological and social.

\subsection{Physical diagnosis}

\subsubsection{Clinic and laboratory}

The laboratory tests serve to establish the physical diagnosis, to follow the course of disease, and to identify adverse effects of therapies. These might include hemoglobin levels, platelet and leukocyte counts, erythrocyte sedimentation rate, urinalysis, and serum levels of creatinine or albumin, ANA, antibodies to double-stranded DNA (dsDNA), antibodies to $\mathrm{Sm}$, antibodies antiphospholipid, anti-Ro, polyclonal gammaglobulinaemia, complement 


\begin{tabular}{|c|c|}
\hline Criterion & Definition \\
\hline 1. Malar Rash & $\begin{array}{l}\text { Fixed erythema flat or raised, over the malar eminences, } \\
\text { tending to spare the nasolabial folds }\end{array}$ \\
\hline 2. Discoid rash & $\begin{array}{l}\text { Erythematous raised patches with adherent keratotic } \\
\text { scaling and follicular plugging; atrophic scarring may } \\
\text { occur in older lesion }\end{array}$ \\
\hline 3. Photosensitivity & $\begin{array}{l}\text { Skin rash as a result of unusual reaction to sunlight, by } \\
\text { patient history or physician observation }\end{array}$ \\
\hline 4. Oral ulcers & $\begin{array}{l}\text { Oral or nasopharyngeal ulceration, usually painless, } \\
\text { observed by physician }\end{array}$ \\
\hline 5. Nonerosive Arthritis & $\begin{array}{l}\text { Involving } 2 \text { or more peripheral joints characterized by } \\
\text { tenderness, swelling, or effusion }\end{array}$ \\
\hline 6. Pleuritis or Pericarditis & $\begin{array}{l}\text { 1 Pleuritis - convincing history of pleuritic pain or rubbing } \\
\text { heard by a physician or evidence of pleural effusion } \\
\text { 1. OR } \\
\text { 2. Pericarditis - documented by electrocardiogram or rub } \\
\text { or evidence of pericardial effusion }\end{array}$ \\
\hline 7. Renal Disorder & $\begin{array}{l}\text { 1. Persistent proteinuria }>0.5 \text { grams per day or }>\text { than } 3+\text { if } \\
\text { quantitation not peformed } \\
\text { 1. OR } \\
\text { 2. Cellular casts -may be red cell, hemoglobin, granular, } \\
\text { tubular, or mixed }\end{array}$ \\
\hline 8. Neurologic Disorder & $\begin{array}{l}\text { 1. Seizures - in the absence of offending drugs or known } \\
\text { metabolic derangements; e.g., uremia, ketoacidosis, or } \\
\text { electrolyte imbalance } \\
\text { 1.OR } \\
\text { 2. Psychosis - in the absence of offending drugs or known } \\
\text { metabolic derangements, e.g., uremia, ketoacidosis, or } \\
\text { electrolyte imbalance }\end{array}$ \\
\hline 9. Hematologic Disorder & $\begin{array}{l}\text { 1 Hemolytic anemia }- \text { with reticulocytosis } \\
\text { 1. OR } \\
\text { 2. Leukopenia }--<4,000 / \mathrm{mm} 3 \text { on } \geq 2 \text { occasions } \\
\text { 1. OR } \\
\text { 3. Lyphopenia }--<1,500 / \mathrm{mm} 3 \text { on } \geq 2 \text { occaions } \\
\text { 1. OR } \\
\text { 4. Thrombocytopenia }--<100,000 / \mathrm{mm} 3 \text { in the absence of } \\
\text { offending drugs }\end{array}$ \\
\hline 10. Immulogic Disorder & $\begin{array}{l}\text { 1. Anti- DNA: antibody to native DNA in abnormal titer } \\
\text { 1. OR } \\
\text { 2. Anti-Sm: presence of antibody to Sm nuclear antigen } \\
\text { 1. OR } \\
\text { 3. Positive finding of antiphospholipid anibodies on: } \\
\text { 1.1-an abnormal serum level of IgG or anticardiolipin } \\
\text { antibodies } \\
\text { 2.2. a positive test result for lupus anticoagulant using a } \\
\text { standard method, or } \\
\text { 3.3.a false-positive test result for at least } 6 \text { months } \\
\text { confimed by Treponema pallidum immobilization or } \\
\text { fluorescent treponemal antibody absorption test }\end{array}$ \\
\hline 11. Positive Antinuclear Antibody & $\begin{array}{l}\text { An abnormal titer of antinuclear antibody by } \\
\text { immunofluorescence or an equivalent assay at any point in } \\
\text { time an in the absence of drugs }\end{array}$ \\
\hline
\end{tabular}

Table 1. 1997 Update of the 1982 American College of Rheumatology Revised Criteria for Classification of Systemic Lupus Erythematosus Criterion. 
values (C3 and C4), IFN-inducible genes, soluble IL-2, and urinary adiponectin or monocyte chemotactic protein 1 .

In the diagnosis of SLE there is no single symptom or finding that is sufficient in itself, it is based on the clinical and the laboratory and on the American Rheumatism Association (ARA) classification criteria. Any combination of $\geq 4$ of 11 criteria makes it likely that the patient has SLE. See TABLE 1.

Antinuclear antibodies (ANA) are positive in more $98 \%$ of patients during the course of disease; repeated negative tests suggest that the diagnosis is not SLE. The antibodies to double-stranded DNA and antibodies to the Sm antigen, specific for SLE, with compatible clinical favor the diagnosis. The presence in an individual of multiple autoantibodies without clinical symptoms should not be considered diagnostic for SLE, although such persons are at increased risk since clinical SLE begins in most patients years after autoantibodies appear.(Nakashima et al, 2011)

\subsubsection{Disease activity and damage caused by SLE}

\subsubsection{Disease activity}

The disease activity indices have been created at standardizing the SLE activity assessment. Some of such indices are: European Consensus Lupus Activity Measurement (ECLAM), Lupus Activity Index (LAI), British Isles Lupus Assessment Group (BILAG), Lupus symptom inventory (LSI) and Systemic Lupus Erythematosus Disease Activity Index (SLEDAI).

The ECLAM assesses disease activity over the last month, and comprises 15 clinical and laboratory parameters. Its scores ranges are from 0 to 10. (Griffiths et al, 2005)

The LAI comprises four scores to assess clinical activity: physician's global evaluation, opinion of the doctor about disease severity, laboratory findings and immunosuppressive treatment. Its scores ranges are from 0 to 3. (Griffiths et al, 2005)

The BILAG index measures SLE disease activity. It is composed of eight organ-based systems: general symptoms, mucocutaneous, respiratory, cardiovascular, neurological, musculoskeletal, renal and hematological. It is represented with alphabetical letters depending of the clinical characteristics present and their behavior during one month. BILAG " $\mathrm{A}$ " represents the presence of one or more severe SLE characteristics. BILAG " $\mathrm{B}$ " indicates more moderate characteristics of the disease. BILAG " $C$ " includes mild symptomatic characteristics. BILAG " $\mathrm{D}$ " represents the previous activity. BILAG " $\mathrm{E}$ " indicates that a system has never been involved. (Isenberg et al, 2005)

The LSI measures clinical activity in the last month. It includes five main symptoms: flares, headaches, joint inflammation, muscles and weakness. Its score ranges are from 1 to 5 . The higher score is the symptoms with more severity (Duvdevany et al, 2011)

The SLEDAI assesses disease activity in the previous ten days. It evaluates the organ affected, clinical and laboratory parameters. The scores greater than 8 indicates active disease. A three-point variation between medical visits indicates disease activation, and variations greater than or equal to 12 points mean severe activity. It was reviewed in the year 2000, originating SLEDAI-2K. The modifications included the persistence of rash, mucosal ulcers, alopecia, and proteinuria greater than 0.5 in $24 \mathrm{~h}$ and had ability to differentiate clearly active patients from inactive ones or those with minimum activity. (Freire al, 2011) 


\subsubsection{Damage caused by SLE}

The damage indices in organ-based systems can be used as a health measure in patients with chronic diseases. The damage caused by SLE has reference a symptom present at least six months that develops in tissue damage which produces irreversible organ damage. It detects damages in patients which can have resulted from disease activity or treatment or comorbidities.

The ACR published the Systemic Lupus International Collaborating Clinics/American College of Rheumatology - Damage Index (SLICC/ACR-DI), in 1996. This instrument approaches 12 organ-based systems. The damages caused by SLE affect to patients who result in physical or/and mental disabilities, worsening the patient's quality of life, which is an important indicator of the health status of patients with chronic diseases. (Freire al, 2011)

\subsection{Psychological and social diagnosis}

The committee on Outcome Measures in Rheumatology Clinical Trials (OMERACT) of the ACR has recognized the importance of measure function and wellbeing from the patient's view as a criterion to determine clinical improvement.

The psychological and social diagnosis can be obtain through data collection via a semistructured interview performed by the same physician and measured about the illness perception of the own patient, experienced thought and behavior by chronic illness, the role of personality and coping with stressful life situations and social relationships. (Freire et al, 2011; Ramírez, 2007)

\subsubsection{IIIness perception}

The model proposes by Leventhal support that self-regulatory patients are active problemsolvers who seek to make sense of illness and form illness perceptions that influence coping strategies.

These representations of illness are composed of cognitions about the name of the illness and its associated symptoms, timeline, causes, personal control and understanding, effectiveness of its treatment. These disease perceptions determine how individuals respond to illness in their emotions, behavior, health care, expectations, attitude to the illness, coping, functioning and cooperation with health professionals. (Kaptein \& Broadbent, 2007; Nowicka-Sauer, 2007)

The methods used to assess illness perception are verbal and nonverbal tools. Among nonverbal are: Pictorial Representation of Illness and Self-Measure (PRISM) and drawing. Among verbal are the Brief-Illness Perception Questionnaire (B-IPQ). (Broadbent et al, 2006; Nowicka-Sauer, 2007).

Pictorial representation of illness and self-measure

Büchi et al have developed the Pictorial Representation of Illness and Self-Measure (PRISM). It is a measure of the "burden of suffering" due to illness from the patient's perspective that includes factors directly related to the disease, disease-related intrusion in relevant aspects of life, like family, work or friendship.

The burden of suffering is a subjective experience arising out of or identified by means of one's awareness of his own states or processes, even clinician with great experience derived from direct observation (facial expression, body posture, signs of sorrow, etc) are unable to detect the inner feelings of their patient. PRISM is a measure, by simplicity of use, that is easily understood by patients and widely accepted by them. 
A red disk, $5 \mathrm{~cm}$ in diameter with magnet on the underside were given to the patient, this disk represents his/her illness and the patient is also presented with a metal board which has a fixed yellow disk $7 \mathrm{~cm}$ in diameter at the bottom right hand corner, this yellow disk represents the patient "self". The patient is then asked "where in your life (board) would you put the (illness) disk at the moment?" The distance between the two disks, representing Illness and Self respectively, is inversely related to the burden of the illness. This distance, measured is called the Self- Illness Separation (SIS). The possible range of SIS is $0 \pm 27 \mathrm{~cm}$.

PRISM can be used in people with SLE in everyday clinical practice as a quantitative assessment instrument of patient-focussed health. (Buchi et al, 1998; Buchi et al, 2000)

\section{Drawing}

The drawings allow to assess patients views on how are the heterogeneity of clinical presentations, variety of illness perception, understanding and experiences of the SLE patients. This method help to talk, it makes the patients open up to their emotions, views, and experiences. It improves understanding of these patients in a short amount of time. Together with questionnaire assessment, the drawings can be an important source of information on how the illness can be experienced and felt and how it influences patients emotions and behaviors. (Daleboudt et al, 2011; Nowicka-Sauer, 2007)

Brief-Illness Perception Questionnaire (B-IPQ)

The B-IPQ contains eight items to score on a scale from 0 to 10 and one open-ended question where the participants have to state the three most important causes for their disease. A mean score is calculated for every scale and the reported causes can be grouped into categories on the basis of common themes. The B-IPQ has been shown to be a valid and reliable measure to assess illness perceptions in ill populations, but no validation for patients with SLE has been done. (Broadbent et al, 2006).

\subsubsection{Cognitive-behavioral analysis}

The experience of chronic illness, one like SLE, could become for the patient the focus of all its daily attention, decreasing the time devoted to family, friends, work, or developing as a person. The ill could focus his time on trying to control or avoid his disease with its emotions, sensations, memories, or thoughts producing human suffering that restrict healthy behavior.

There are measures widely used for clinical outcomes, that assess human sufferers produced by chronic illness. These are: Beck Depression Inventory (BDI), Pain Anxiety Symptoms Scale (PASS), Sickness Impact Profile (SIP), Chronic Pain Acceptance Questionnaire (CPAQ), Mindful Attention Awareness Scale (MAAS), Chronic Pain Values Inventory (CPVI).

\section{Beck Depression Inventory}

The Beck Depression Inventory (BDI) is a measure of depression and general emotional distress. It has 21 items. Each scored goes from zero (neutral) to three (maximum severity). The BDI range is from zero to sixty three. The twenty is a cutoff for clinically significant symptoms. (Beck et al, 1988; McCracken et al, 2007)

\section{Pain Anxiety Symptoms Scale}

The Pain Anxiety Symptoms Scale (PASS) is a measure of anxiety responses and avoidance related to chronic pain. The original version is a 40-item measure. Patients indicate the frequency of anxiety from zero (never) to five (always). The total score ranges from zero to 
two hundred. The PASS includes subscales: cognitive anxiety symptoms, escape and avoidance, fearful thinking and physiological anxiety responses.

The PASS-20 is a new version of PASS-40. It is a 20-item measure. It assesses of fear, avoidance, cognitive, and anxiety responses related to chronic pain. The rate each item goes from zero (never) to five (always) indicating how the patients do or experience each of the actions or thoughts described. (McCracken et al, 2004; McCracken \& Yang, 2006; McCracken et al, 2007; Roelofs et al, 2004)

\section{Sickness Impact Profile}

The Sickness Impact Profile (SIP) is used to assess physical and psychosocial disability on daily functioning. It is a 136-item measure. It has three domains (physical, psychosocial and other aspects of disability) and twelve categories of daily functioning. The categories can be scored separately or combined with domains. The categories in the physical domain are ambulation, mobility, body care and movement. The categories in the psychosocial domain include social interaction, alertness behavior and emotional behavior. The categories in the other domain are sleep and rest, eating, home management, recreation and pastimes, work and communication. The patients, when answering the SIP, endorse statements that describe problems in relation to their health. All scores range from 0 to 1 . Higher scores indicate greater disability. (McCracken \& Yang, 2006; McCracken et al, 2007)

\section{Chronic Pain Acceptance Questionnaire}

The Chronic Pain Acceptance Questionnaire (CPAQ) is a measure of acceptance of chronic pain. It is a 20-item inventory. Each item has a scale of zero (never true) to six (always true). The total score ranges from zero to one hundred and twenty. It has two subscales: activity engagement (eleven items) and pain willingness (nine items). The activity engagement measures tendency to perform usual daily activities regardless of pain present. The pain willingness measures the relative absence of attempts to control or avoid pain present. (McCracken et al, 2004; McCracken \& Yang, 2006; McCracken et al, 2007)

\section{Mindful Attention Awareness Scale}

The Mindful Attention Awareness Scale (MAAS) is a measure of mindfulness. It is a 15-item inventory. Each item is rated on a scale from one (almost always) to six (almost never). The items content reflects the opposite of mindfulness or mindlessness. The items of the lower frequency are taken to represent a higher level of mindfulness. The items greater than eighty correlate with measures of emotional distress and physical symptoms. (Brown and Ryan, 2003; McCracken et al, 2007)

\section{Chronic Pain Values Inventory}

The Chronic Pain Values Inventory (CPVI) is based on the acceptance and commitment therapy. It assesses two scores: success and the discrepancy between importance and success in six domains of patient values. The first set considers the values and rates the importance of these patients in each domain. The second set rates how these persons have lived according to their values in each domain. The values domains are: family, intimate relations, friends, work, health, and growth or learning. The rates of each item go from zero (not at all important/successful) to five (extremely important/successful). Low success in living in accord with an unimportant value produces less suffering than low success living in accord with important value. (McCracken \& Yang, 2006) 


\subsubsection{Personality and coping variables}

The capacities of patient to cope with stress to go off defence mechanisms that result in the psychological response to determine as these persons are living with the SLE. (Eriksson \& Lindstrom, 2005)

\subsubsection{Defence mechanisms}

The defence mechanisms are defined by American Psychiatric Association as "automatic psychological processes that protect the individual against anxiety and from the awareness of internal or external dangers and stressors, mediating the individual's reactions to emotional conflicts and to internal or external stressors". (American Psychiatric Association. Diagnostic and Statistical Manual of Mental Disorders DSM-IV-TR, 1994)

The Defence Style Questionnaire (DSQ-88) estimate behaviour indicating four defence styles: namely maladaptive action, image-distorting, self-sacrificing and adaptive styles.

The Hostility and Direction of Hostility Questionnaire (HDHQ) provides a measure of hostility that reflects an attitudinal personality trait and shows the participant's reaction to frustrating occurrences. These questionnaires have been used with rheumatic patients. (Bai et al, 2009; Hyphantis et al,2006; Hyphantis, 2010)

\subsubsection{Sense of coherence}

The sense of coherence (SOC) introduced by Antonovsky, is defined as "a global life orientation that expresses the extent to which one has a pervasive, enduring though dynamic sense of confidence that the stimuli deriving from one's internal and external environments in the course of living are structural, predictable, and explicable; the resources are available to one to meet the demands posed by the stimuli; and these demands are worthy of investment and engagement".

The SOC scale assesses the three dimensions: comprehensibility, manageability, and meaningfulness. It is an instrument measuring of global orientation how people manage stressful situations, not to measure each of the three core components separately.

In patients with SLE, have been found correlations between SOC scores and physical and psychological quality of life components. The use of SOC scale detect those patients who are coping poorly with the illness because they have poor psychological resources, in order to promote psychotherapeutic interventions that improve patients' QOL. (Abu-Shakra et al, 2006; Hyphantis et al, 2011)

\subsubsection{Quality of life}

The quality of life (QOL) has been defined by WHO as "individuals perceptions of their position in life in the context of the culture and value systems in which they live and in relation to their goals, expectations, standards and concerns". (WHOQOL Group, 1995)

As health-related QOL scales are measures centered on the patient's opinion. It assessments the patient's health status throughout the disease and their satisfaction with treatment. These instruments are very used because these persons are the most interested in their own outcome. (Freire et al, 2011)

The instruments for QOL assessment can be self-administered or interview-administered. It can be generic or specific for a certain disease. Some generic instruments are the WHOQOL and Short Form 36-item Health Survey Questionnaire (SF-36). Other specific instruments are Systemic Lupus Erythematosus Symptom Checklist (SSC), Systemic Lupus Erythematosus Quality of Life Questionnaire (SLEQOL), Systemic Lupus Erythematosus Needs Questionnaire (SLENQ), Lupus Quality of Life (LupusQOL) 


\section{WHOQOL}

The World Health Organization (WHO) has developed an international quality of life assessment. This measure shows physical, psychological and social well-being of patients connecting with the WHO's definition of quality of life. In clinical practice, the WHOQOL assessments help clinicians to discover the areas in which a patient is most affected by disease, and to decide about treatment.

The WHOQOL exists in twenty nine languages, contain hundred questions group by domains and sub-domains of quality of life. These are: I Physical Capacity (1 Pain and discomfort, 2 Energy and fatigue, 3 Sleep and rest), II Psychological (4 Positive feelings, 5 Thinking, learning, memory and concentration, 6 Self-esteem, 7 Bodily image and appearance, 8 Negative feelings), III Level of Independence (9 Mobility, 10 Activities of daily living, 11 Dependence on medication or treatments, 12 Work capacity), IV Social Relationships (13 Personal relationships, 14 Social support, 15 Sexual activity), V Environment (16 Physical safety and security, 17 Home environment, 18 Financial resources, 19 Health and social care: accessibility and quality, 20 Opportunities for acquiring new information and skills, 21 Participation in and opportunities for recreation/ leisure activities, 22 Physical environment (pollution/noise/traffic/climate), 23 Transport), VI Spirituality/Religion/ Personal Beliefs. (WHOQOL Group, 1995).

\section{Short Form 36-item Health Survey Questionnaire}

The Short Form 36-item Health Survey Questionnaire (SF-36) is a generic instrument for QOL assessment. It is a questionnaire with thirty-six items, grouped into the eight domains, which are: physical function, role limitations due to physical health, pain, general health perception, vitality, social function, role limitations due to emotional problems, and mental health. It summarize the results in two areas: physical and psychological. The score ranges are from zero to hundred and are directly proportional to the state of health.. There are validation studies in SLE patients, in a variety of socio-cultural contexts using many languages SF-36 versions. The SF-36 was recommended as the instrument of choice for measuring HRQOL in SLE. (Freire el al, 2011; Thumboo \& Strand, 2007)

\section{Systemic Lupus Erythematosus Symptom Checklist}

The Systemic Lupus Erythematosus Symptom Checklist (SSC) measure the impact of the disease and its treatment on the individual. This questionnaire study 38 symptoms in a fourpoint scale, where zero is the best health status and four, the worst. (Freire et el, 2011; Sanchez et al, 2009; Thumboo \& Strand, 2007)

\section{Systemic Lupus Erythematosus Quality of Life Questionnaire}

The Systemic Lupus Erythematosus Quality of Life Questionnaire (SLEQOL) has 40 items into the six domains: physical function, occupational activity, symptoms, treatment, mood and self-image. The scores vary from one to seven, and the lower (fourty) the score is the best the QOL and the higher (two hundred and eighty) the score is the worse QOL. This questionnaire showed to have more sensitivity to changes over time than SF-36. (Freire et el, 2011; Sanchez et al, 2009; Thumboo \& Strand, 2007)

\section{Systemic Lupus Erythematosus Needs Questionnaire}

The Systemic Lupus Erythematosus Needs Questionnaire (SLENQ) has seven domains: that assess the following needs: psychological-spiritual-existential, health services, health 
information, physical, social support, daily living, and employment. This questionnaire showed moderate correlations with SF-36. (Moses et al, 2007; Freire et el, 2011).

Lupus Quality of Life

The Lupus Quality of Life (LupusQOL) contains thirty four items in eight domains: physical health, emotional health, body image, pain, planning, fatigue, intimate relationships and burden to others. (Freire et el, 2011; McElhone et al, 2007; Sanchez et al, 2009; Thumboo \& Strand, 2007)

Cross-sectional studies and prospective studies have identified the age, the duration, the activity and damage disease, some specific manifestations of SLE as fatigue, pain or endstage renal failure, the corticosteroids or cytotoxic, the knowledge of lupus, the illness related behaviours, the educational status, the self-efficacy, the learned helplessness, the ability to work, the home environment and the social support as factors associated may influence health-related quality of life (HRQOL) in SLE patients. (McElhone K et al, 2006; Navarrete-Navarrete et al, 2010; Thumboo \& Strand, 2007)

\section{Treatment}

The SLE is no curable and complete remissions are rare, sometimes is cyclical and sometimes is progressive, is heterogeneous in manifestations and has significant mortality risk. It is a disease that requires lifelong treatment.

SLE may have a higher impact on patients' life than other chronic illnesses, and the level of impact may be influenced by type of treatment. SLE is a disease that can significantly impact physiological, psychological and social functioning, influencing in health-related quality of life of the patients. The pharmacologic and non-pharmacologic therapies may have an additive or synergistic effect on improving on these patients HRQOL (Daleboudt et al, 2011; Thumboo \& Strand, 2007).

\subsection{Patient-centred care}

The treatment of SLE's people should be patient-centred ensuring that the patients are treated with dignity and respect. Good communication between doctors and patients is essential. These ills and their families and carers need a high-quality communication, supported by evidence-based information that provides treatment and care based on best practice. Patients should have the opportunity to be involved in the decisions about their treatment and care. The physician should take into account needs and preferences of the patients. Families and carers should have the information and support they need. Information, treatment and care should be given at patients, families and carers by culturally appropriate written information tailored to their needs. (Michalski \& Kodner , 2010; van der Giesen et al, 2007; Villanueva, 2009)

\subsection{Multidisciplinary treatment}

SLE is a complex disease. Healthcare professionals of these patients must pay careful attention to all items of illness (physical, psychological, family and social) in multidisciplinary cooperation. It is the most frequent that patient comes at primary care physicians. The American College of Rheumatology Ad Hoc Committee on SLE guidelines recommends that primary care physicians should refer SLE patients to rheumatologists to establish SLE definitive diagnosis, activity and severity disease and treatment of general 
disease and some medication side effects. Rheumatologists should work with a multidisciplinary team allowing coordinated care of patient. This includes family physicians, other specialist physicians, psychotherapies, rehabilitations, nurses and social workers. Family Medicine is a specialty focused person-centred care. Competent and polyvalent family physicians may be allowed to attend the patient in his/her whole life. From primary care should monitored ill a long time and treated when presents other pathologies or some medication side effects (infection, cardiovascular disease, osteoporosis,) or mild symptom SLE. From other specialist physicians should treat damaged major organ. From psychotherapy should teach coping strategies to favor psychosocial adjustment. (Aberer, 2010; Beckerman et al, 2011; Michalski \& Kodner , 2010; Ramírez, 2007; Taylor \& McMurray, 2011; van der Giesen et al, 2007; Villanueva, 2009)

\subsection{Physical treatment}

Medical treatment and a recommended lifestyle are necessary for optimal functioning in life SLE patients.

The pharmacological treatment is always individual. It depends if it is to control acute, severe flares or to develop maintenance strategies that suppress symptoms and prevent organ damage. This therapy also depends on adverse effects of medications, whether disease manifestations are life-threatening or to cause organ damage, whether manifestations are potentially reversible and the best approaches to preventing complications of disease. (Michalski \& Kodner , 2010; Taylor \& McMurray, 2011; YildirimTorner C \& Diamond B, 2011.)

The most important drugs are: nonsteroidal anti-inflammatory drugs, hydroxychloroquine corticosteroids, immunosuppressive drugs (azathioprine, cyclophosphamide, methotrexate, mycophenolate). Almost all patients should take hydroxychloroquine and most corticosteroids with immunosuppressive drugs. With better management, patients with lupus live longer but are at increased risk of disease and treatment-related complications, including infection, cardiovascular disease, and osteoporosis. (Michalski \& Kodner , 2010; Taylor \& McMurray, 2011; Yildiri-Toruner C \& Diamond B, 2011.)

Pharmacologic and biologic therapies reducing disease activity and/or levels of anti-dsDNA antibodies improving HRQOL for SLE patients.(Thumboo \& Strand, 2007; Dall'era \& Chakravarty, 2011)

The damages disease in skin or alopecia can be improved with treatment of these lesions and/or use of cosmetics to camouflage these lesions.

The use of a highly protective broad-spectrum (UVB and UVA) sunscreen can effectively prevent skin photosensitive lesions in patients's SLE. (Kuhn et al, 2011; Obermoser \& Zelger B, 2008 ; Thumboo \& Strand, 2007)

\subsection{Psychological and social treatment}

The psychotherapy programs should help to equip the SLE's patients with knowledge and skills of coping for managing the illness and to build up familiar and social support.

The patients with rheumatic illness experience significant restrictions into their daily life. There are researches that prove that the cognitive behavioral therapy (coping methods and contextual methods) improves on these persons their experience of physical symptom (pain, fatigue), daily activity, psychology and social functioning.

Although there are few researches on SLE's patients, the cognitive behavioral therapy (CBT) (coping methods and contextual methods) reaches above average levels in physical 
functioning, psychic functioning and social functioning obtaining a significant improvement in the HRQOL, independent of the activity level of the disease. (McCracken \& Vowles, 2008; Navarrete-Navarrete et al, 2010; Ramírez, 2007)

\subsubsection{Psychotherapy methods}

The behavioral therapy is in a state of development. Actually, there are three generations. They are based on chosen strategies the two firsts direct change, coping methods, and the third indirect change, contextual methods. The coping methods are focused on control or change in the content of psychological experiences and the contextual methods include acceptance, mindfulness and values. These therapies are characterized: the first by behavioral change, the second by cognitive models and the third by processes of acceptance and values-based action. They are integrative and not exclusive, they encompass each other. In these therapies the problems are rationalized and contextualized and the sensations produced by them can improve experience and acceptance.

The psychotherapy that use coping methods includes: understanding SLE providing information, understanding one's rights as a patient, controlling pain and fatigue oneself, teaching stress management through concept of stress and relaxation techniques (diaphragm breathing and deep muscle relaxation), alternative thought control strategies that help to manage frustration and emotion (self-instructional training and thought stopping), humour and optimism as coping strategies, cognitive restructuring (identifying and discussing the consequences of main errors in thinking, main core beliefs, challenging thoughts), demonstrating problem-solving skills, developing personal strengths, training in social skills (assertiveness techniques, how to say no without feeling bad, asking another person to change their behavior) locating community resources for rehabilitation. (Navarrete-Navarrete et al, 2010; Ng P \& Chan, 2007; Ramírez, 2007; Robles-Ortega \& Peralta-Ramírez, 2006; Sheldon,1995)

The psychotherapy that includes contextual methods is acceptance and commitment therapy (ACT) and mindfulness.

The ACT centers on building positive and flexible behavior patterns rather than removing symptoms carrying up processes of acceptance, contact with the present moment and values-based action. This model includes: acceptance, cognitive defusion, contact with the present moment, self-as-context, values and committed action (Hayes et al, 2006). The studies with this treatment on patient's rheumatic illness are very up to date. (McCracken \& Vowles, 2008)

Mindfulness is a technique and a component of the acceptance and commitment therapy. It can be understood as attention, awareness and reflection of present moment nonjudgmental. This model include: nonconceptual, focused on the present, non-judgmental, intentional, participatory observation, emotional, exploratory and liberating. The researches with this technique on patient's rheumatic are also very up to date. (Germer et al, 2005)

\subsubsection{Psychotherapy in SLE}

The patients with SLE live with fears about the illness because they have nothing or little knowledge about the clinic, treatment and prognosis of the illness. The researches have shown that to improve the understanding of these persons with accurate information of the mechanisms of SLE contribute to a better adjustment to live with their illness because their negative beliefs about it are reduced influencing on their self-esteem. (Ng P \& Chan, 2007) 


\subsubsection{Chronic pain}

The chronic pain is a great suffering for SLE's patient.

The medical and surgical treatments may produce variable results and adverse events and iatrogenic complications on any patient with chronic pain. The use of other means for pain reduction, as the programs of physical activity may reduce pain improving HRQOL in these ills.

The subjective nature of pain makes complicated this problem. The pain is a response to nociception on the patient influenced by genetic, personal history, physiologic state and psychological and social context. And the pain influences on physical, psychological and social functioning.

The patients with chronic pain may be influenced by distressing thoughts and emotions and ineffective behaviors focusing on their pain. The increasing attempts to control pain may be associated with increasing the limits of their functioning interfering with healthy living. An alternative approach, are personal's choice of adaptive responses adjusted to chronic pain. The research has shown the utility of ACT. The experienced pain, with control, allows more healthy activities.

The acceptance-oriented responses to chronic pain may improve physical (disability), psychological (suffering) and social (working) functioning over time. The positive purposes of families and friends, with more patient attitude about behavior pattern, may make easier the processes of acceptance.

The mindfulness-based treatment methods are addressed to these patients suffering chronic pain. The mindfulness is based: present-focused, realistic contact with pain, neutral awareness of pain, change experience pain and effective behavioral. Mindfulness is observation and commitment. The researches show mindfulness may get better well-being of patients with chronic pain. It gives them more realistic experiences and more effective flexible behavioral. (McCracken et al, 2007; Thumboo \& Strand, 2007)

\subsubsection{Fatigue}

Fatigue is lack of energy, physical and mental tiredness. On SLE's patients, it compromises quality of life, reducing psychological well-being, because these difficulties on daily activities affect personal and social life.

Fatigue is present on many chronic ills, for example: multiple sclerosis, cancer, chronic fatigue syndrome, rheumatoid arthritis, SLE.

The physiopathology of fatigue in SLE have been difficult to identify but likely to be multifactorial.

Fatigue may be associated with SLE disease process and with pain, lack of physical exertion, sleep disturbance, depression, anxiety, stressful life events, infection, medication side effects and characteristics of the local environment (lighting and temperature). (Bakshi 2003; Dittner et al, 2004 ; Godaert et al, 2002 ; Neill, 2005 ; Zifko, 2004).

Researches for reducing fatigue in people with SLE are few and show strategies not completely effective in the long-term. The treatment of chronic illnesses fatigue usually combines pharmacological and nonpharmacological therapy. Pharmacological therapy efficacy is questioned in fatigue of SLE's patients and nonpharmacological therapy is essential for her management. This therapy include exercise, rehabilitation programmes and cognitive behavioral therapy. (Godaert et al, 2002)

Studies suggest aerobic exercise is effective for reducing fatigue in some people with SLE. This exercise includes low-impact aerobics, walking, cycling, and jogging. It should be 
appropriate for each ill and take into account individual fluctuations in fatigue intensity, if feasible, it might be executed home-based or in supervised classes. This exercise should begin early in the disease course or following the disease, start with low intensity activities and avoid provoking symptoms, gradually increasing in intensity, duration and frequency, combine aerobic and resistance training where possible. It is recommended to carry out between fifteen and thirty minutes at least three times weekly if it is tolerated. This exercise type appears to be effective in reducing fatigue in patient with cancer and chronic fatigue syndrome. (Mancuso et al, 2010; Stricker et al. 2004 ; Watson \& Mock, 2004).

Fatigue is a variable and subjective experience that may decline inactive life-style disproportionally affecting physical activity, psychological and societal participation. In this case, it might be required to promote interventions of self-management of fatigue and better illness cognitions and coping styles by means of CBT.

Cognitive behavioural therapy helps to identify and to challenge perpetuating factors. These are: insufficient coping with the disease and dysfunctional cognitions about fatigue such as lack of control and catastrophizing (negative thoughts are put into reality perspective), deregulation of sleep (to adhere biologic rhythm and to fixed bedtimes and wake-up times during the day), deregulation of activity (a base level activity and alternating rest and activity should be established), low social interactions (to favor realistic expectations toward the participation in social relations).

Studies show that cognitive behavioural therapy with/without exercise is effective in reducing fatigue in chronic fatigue syndrome, multiple sclerosis, cancer-related fatigue and SLE because it improves self-efficacy, increasing their quality of life. (Edmonds et al, 2004; Navarrete-Navarrete et al, 2010; Neill et al, 2006; Wagner \& Cella, 2004)

\subsubsection{Neuropsychiatric manifestations}

Cognitive dysfunction, anxiety and depression are frequent in patient's SLE. The consequences of SLE living may impact personal life, including interpersonal relationships and professional rol. The majority of SLE patients present depression and emotional distress. These affective disturbances are very rarely attributed to disease activity alone, and may influence psychosocial factors. Cognitive dysfunction may coexists with psychiatric disorders. Their association in SLE is not clear. Some study shows the psychological state of the ill may influence self-reporting of cognitive problems (Farrin et al, 2003; Kozora et al, 2006; Kozora et al, 2007; Nowicka-Sauer et al, 2011; Panopalis et al, 2007; Vogel et al, 2011; Zakeri et al, 2011.)

Neuropsychiatric manifestations should be diagnosed and treated in these patients first as if they had not SLE, and secondarily as if they had it. (Bertsias et al, 2010)

Clinical guideline about care of patients with depression and a chronic physical health problem recommend physical activity programme and cognitive behavioural therapy. (NICE, 2009)

Cognitive behavioural therapy sets up role cognitive representations or perceptions and emotional responses of patient's SLE that can influence individual's ability to manage his illness by selecting coping strategies. The ill may organize an individual's response around five cognitives. These include: representation of their illness, perceived duration, unpredictability, control, perceived of severity and cause. There are researches that show better depressive symptoms and cognitive dysfunction in patient SLE following cognitive behavioural therapy.(Bertsias \& Boumpas, 2010 ; Bertsias et al, 2010; Greco et al, 2004; Philip et al, 2009) 


\section{Conclusion}

Systemic lupus erythematosus (SLE) is a chronic inflammatory autoimmune disease of unknown etiology, with predominance of the female sex in their childbearing years.

SLE affects heterogeneity multiple organs of the body and presents aberrant immunological findings. The clinical course and prognosis is unpredictable. It can affect sociopsychologically to patients experiencing high levels of emotional distress by affecting physical, pharmacology treatment, their own worries about illness, abnormal illness-related behaviours and affecting social life.

The integral diagnosis in the patients with SLE include the aspects: physical, psychological and social. The physical diagnosis of SLE is based on the clinical and the laboratory and on the American Rheumatism Association (ARA) classification criteria. The psychological and social diagnosis can be obtain through data collection via a semi-structured interview performed by the same physician and measure about the illness perception of the own patient, experienced thought and behavior by chronic illness, the role of personality and coping with stressful life situations and social relationships.

The integral treatment of patient's SLE include pharmacological and non-pharmacological therapies that may have an additive or synergistic effect on these patients. These treatment should be patient-centred favouring high-quality communication between doctors and patients with their families and carers supported by evidence-based information that provides treatment and care based on best practice. These patients should be treatment by multidisciplinary team that include family physicians, rheumatologists, other specialist physicians, psychotherapies, rehabilitations, nurses and social workers. Pharmacological treatment and recommended lifestyle are always individual and necessary for optimal functioning in life SLE patients. The psychotherapy should help to equip the SLE's patients, that experience significant restrictions into their daily life, with knowledge and skills of coping for managing the illness and to build up familiar and social support. The cognitive behavioural therapy (coping methods: behavioural change and cognitive models, and contextual methods: acceptance and commitment therapy and mindfulness) improves on these persons their experience of physical symptom (pain, fatigue,...), daily activity, psychology and social functioning.

\section{Key points}

1. The SLE is a chronic inflammatory autoimmune disease of unknown etiology with predominance on the female sex in their childbearing years.

2. The SLE affects heterogeneity multiple organs of the body and presents aberrant immunological findings.

3. The clinical course and prognosis of SLE is unpredictable, it is a disease no cure.

4. The SLE affect patient's bio-psycho-social unit.

5. The integral diagnosis in patients with SLE includes : physical, psychological and social aspects.

6. The treatment of SLE patients should be physical, psychological and social.

7. The treatment of SLE's people should be patient-centred.

8. Healthcare to SLE patients should be multidisciplinary including rheumatologists, family physicians, other specialist physicians, psychotherapies, rehabilitations, nurses and social workers. 
9. Medical treatment and a recommended lifestyle are necessary for optimal functioning in the life of SLE patients.

10. The psychotherapy programs should help to equip the SLE's patients with knowledge and skills of coping for managing the illness and to build up familiar and social support.

11. The cognitive behavioural therapy (coping methods and contextual methods) improves on the persons' SLE their experience of physical symptom (pain, fatigue, neuropsychiatric manifestations), daily activity, psychology and social functioning.

\section{References}

Aberer E. (2010). Epidemiologic, socioeconomic and psychosocial aspects in lupus erythematosus Lupus (2010) 19, 1118-1124

Abu-Shakra M, Keren A, Livshitz I. (2006). Sense of coherence and its impact on quality of life of patients with systemic lupus erythematosus. Lupus 2006; 15: 32-37.

American Psychiatric Association. Diagnostic and Statistical Manual of Mental Disorders DSM-IV-TR (4th ed.,text rev.). Washington, American Psychiatric Press, 1994.

Bai M, Tomenson B, Creed F.(2009). The role of psychological distress and personality variables in the disablement process in rheumatoid arthritis. Scand J Rheumatol 2009; 38: 419-430.

Baker K \& Pope J. (2009). Employment and work disability in systemic lupus erythematosus: a systematic review. Rheumatology (Oxford).2009 Mar;48(3):281-4. Epub 2009 Jan 19.

Bakshi R. (2003) Fatigue associated with multiple sclerosis: diagnosis, impact and management. Multiple Sclerosis 9(3), 219-227.

Beck AT, Steer RA, Garbin MG. (1988). Psychometric properties of the Beck Depression Inventory: twenty-five years of evaluation. Clin Psychol Rev 1988;8:77-100.

Beckerman N. L., Auerbach Ch., Blanco I. (2011). Psychosocial dimensions of SLE: implications for the health care team. Journal of Multidisciplinary Healthcare 2011:4 63-72

Bertsias GK, Boumpas DT. (2010). Pathogenesis, diagnosis and management of neuropsychiatric SLE manifestations. Nat Rev Rheumatol. Jun 6(6):358-67.

Bertsias GK, J P A Ioannidis, M Aringer, E Bollen, S Bombardieri, I N Bruce, R Cervera, M Dalakas, A Doria, J G Hanly, T W J Huizinga, D Isenberg, C Kallenberg, J C Piette, M Schneider, N Scolding, J Smolen, A Stara,I Tassiulas, M Tektonidou, A Tincani, M A van Buchem, R van Vollenhoven, M Ward, C Gordon, D T Boumpas (2010). EULAR recommendations for the management of systemic lupus erythematosus with neuropsychiatric manifestations: report of a task force of the EULAR standing committee for clinical affairs. Ann Rheum Dis 69:2074-2082. doi:10.1136/ard.2010.130476

Broadbent E, Petrie KJ, Main J, Weinman J. (2006). The brief illness perception questionnaire. J Psychosom Res 2006; 60: 631-637.

Brown KW, Ryan RM. (2003). The benefits of being present: mindfulness and its role in psychological well-being. J Pers Soc Psychol 2003; 84:822-48. 
Büchi S, Villiger P, Kauer Y, Klaghofer R, Sensky T \& Stoll T. (2000). PRISM (Pictorial Representation of Illness and Self Measure) a novel visual method to assess the global burden of illness in patients with systemic lupus erythematosus. Lupus (2000) 9, 368 \pm 373 .

Büchi S, Sensky T, Sharpe L, Timberlake N. (1998). Graphic representation of illness: a novel method of measuring patients' perceptions of the impact of illness. Psychother Psychosom 1998; 67: 222 225.

Burgos PI, Alarcón GS, McGwin G Jr, Crews KQ, Reveille JD, Vilá LM. (2009). Disease activity and damage are not associated with increased levels of fatigue in systemic lupus erythematosus patients from a multiethnic cohort: LXVII. Arthritis Rheum.2009 Sep 15;61(9):1179-86.

Chaiamnuay S, Bertoli AM, Fernández M Apte M, Vilá LM, Reveille JD, Alarcón GS. (2007). The impact of increased body mass index on systemic lupus erythematosus: data from LUMINA, a multiethnic cohort. J Clin Rheumatol. 2007 Jun;13(3):128-33.

Chuang TH, Lin KC, Gau ML. (2010). Validation of the braden self-help model in women with systemic lupus erythematosus. J Nurs Res.2010 Sep;18(3):206-14.

Dalléra M, Chakravarty EF. (2011). Treatment of Mild, Moderate, and Severe Lupus Erythematosus: Focus on New Therapies. urr Rheumatol Rep. 2011 May 17.

Daleboudt GMN, Broadbent E, Berger SP \& Kaptein AA. (2011). Illness perceptions in patients with systemic lupus erythematosus and proliferative lupus nephritis. Lupus (2011) 20, 290-298

Dittner A., Wessley S. \& Brown R. (2004) The assessment of fatigue - a practical guide for clinicians and researchers. Journal of Psychosomatic Research 56(2), 157-170.

Duvdevany I, Cohen M, Minsker-Valtzer A \& Lorber M. (2011). Psychological correlates of adherence to self-care, disease activity and functioning in persons with systemic lupus erythematosus. Lupus (2011) 20, 14-22

Edmonds M., McGuire H. \& Price J. (2004) Exercise therapy for chronic fatigue syndrome. The Cochrane Database of Systematic Reviews, issue 3, art no.: CD003200.pub2.

Errol J. Philip, M.A, Helen Lindner, Ph.D., Leah Lederman, B.B.Sc. (2009). Relationship of illness perceptions with depression among individuals diagnosed with lupus depression and anxiety. 2009, 26:575-582

Farrin L, Hull L, Unwin C, Wykes T, David A. (2003). Effects of depressed mood on objective and subjective measures of attention. J Neuropsychiatry Clin Neurosci 15: 98-104.

Freire, Souto, Ciconelli3. (2011). Assessment measures in systemic lupus erythematosus. Rev Bras Reumatol 2011;51(1):70-80

Germer, C.K., Siegel, R.D., \& Fulton, P.R. (2005). Mindfulness and psychotherapy. New York: GuilfordPress.

Giesen van der, Nelissen, Rozing, Arendzen, de Jong, Wolterbeek, Vliet Vlieland. (2007). A Multidisciplinary Hand Clinic for Patients with Rheumatic Diseases: a Pilot Study Journal of Hand Therapy. July-September 2007

Griffiths B, Mosca M, Gordon C. (2005). Assessment of patients with systemic lupus erythematosus and the use of lupus disease activity indices. Best Pract Res Clin Rheumatol 2005; 19(5):685-708. 
Hyphantis T. (2010). The Greek version of the Defense Style Questionnaire: psychometric properties in three different samples. Compr Psychiatry 2010; 51: 618-629.

Hyphantis T, Bai L, Siafaka V. (2006). Psychological distress and personality traits in early rheumatoid arthritis: a preliminary survey. Rheum Int 2006; 26: 828-836.

Hyphantis T, Palieraki K, Voulgari PV, Tsifetaki N \& Drosos AA (2011). Coping with healthstressors and defence styles associated with health-related quality of life in patients with systemic lupus erythematosus. Lupus (2011) 0, 1-11

Isenberg DA, Rahman A, Allen E, Farewell V, Akil M, Bruce IN. (2005). Development and initial validation of an updated version of the British Isles Lupus Assessment Groups disease activity index for patients with systemic lupus erythematosus. Rheumatology (Oxford) 2005.

Javierre BM, Richardson B. (2011). A new epigenetic challenge: systemic lupus erythematosus. Adv Exp Med Biol. 2011;711:117-36.

Jong Z.de, Wolterbeek R., Vliet Vlieland T.P.M., (2007). A Multidisciplinary Hand Clinic for Patients with Rheumatic Diseases: a Pilot Study. Journal of Hand Therapy (JulySeptember 2007) doi:10.1197/j.jht.2007.04.004

Godaert G.L., Hartkamp A., Geenen R., Garssen A., Kruize A.A., Bijlsma J.W. \& Derksen R.H. (2002) Fatigue in daily life in patients with primary Sjogren's syndrome and systemic lupus erythematosus. Annals of the New York Academy of Sciences 966, 320-326.

Greco CM, Rudy TE, Manzi S. (2004) Effects of a stress-reduction program on psychological function, pain, and physical function of systemic lupus erythematosus patients: a randomized controlled trial. Arthritis Rheum $51: 625$ - 34 .

Hayes, S. C., Luoma, J. B., Bond, F. W., Masuda, A., Lillis, J. (2006). Acceptance and Commitment Therapy: Model, processes and outcomes. Behaviour Research and Therapy, 44, 1-25.

Jarpa E, Babul M, Calderón J, González M, Martínez ME, Bravo-Zehnder M, Henríquez C, Jacobelli S, González A, Massardo L (2011). Common mental disorders and psychological distress in systemic lupus erythematosus are not associated with disease activity. Lupus. 2011 Jan;20(1):58-66. Epub 2010 Nov 15.

Kaptein AA, Broadbent E. (2007). Illness cognition assessment. In: Ayers S, Baum A, McManus C, et al. Handbook of Psychology, Health and Medicine, 2nd ed. Cambridge: Cambridge University Press; 2007. p. 268-273.

Koike T. (2011). The new era of autoimmune disease research. Arthritis Res Ther. 2011 May 31;13(3):113.

Kozora E, Arciniegas DB, Zhang L, West S. (2007). Neuropsychological patterns in systemic lupus erythematosus patients with depression. Arthritis Res Ther; 9: R48

Kozora E, Ellison MC, West S. (2006). Depression, fatigue, and pain in systemic lupus erythematosus (SLE): relationship to the American College of Rheumatology SLE neuropsychological battery. Arthritis Rheum 55: 628-635.

Kuhn A., Gensch K., Haust M., Meuth AM., Boyer F., Dupuy P, Lehmann P., Metze D, Ruzicka T. (2011). Photoprotective effects of a broad-spectrum sunscreen in ultraviolet-induced cutaneous lupus erythematosus: A randomized, vehicle- 
controlled, double-blind study. J Am Acad Dermatol Vol.64, No.1 (January 2011) ; 64:37-48.

Lance M. McCracken. (2007) Jeremy Gauntlett-Gilbert, Kevin E. Vowles (2007). The role of mindfulness in a contextual cognitive-behavioral analysis of chronic pain-related suffering and disability. Pain 131 (2007) 63-69

Eriksson M, Lindstrom B. (2005). Validity of Antonovsky's sense of coherence scale: a systematic review. J Epidemiol Community. Health 2005; 59: 460-466.

Mancuso CA, Perna M, Sargent AB \& Salmon JE. (2010). Perceptions and measurements of physical activity in patients with systemic lupus erythematosus .Lupus (February 2010) 0, 1-12

McCracken L.M., Vowles K. E., Gauntlett-Gilbert J. (2007). A Prospective Investigation of Acceptance and Control-Oriented Coping with Chronic Pain. J Behav Med 30:339_ 349

McCracken L.M. \& Vowles K.E. (2008) A Prospective Analysis of Acceptance of Pain and Values-Based Action in Patients With Chronic Pain. Health Psychology Vol. 27, No. $2,215-220$

McCracken L M., MacKichan F, Eccleston C. (2007). Contextual cognitive-behavioral therapy for severely disabled chronic pain sufferers: Effectiveness and clinically significant change. European Journal of Pain 11 (2007) 314-322

McCracken LM, Gauntlett-Gilbert J, Vowles KE. (2007). The role of mindfulness in a contextual cognitive-behavioral analysis of chronic pain-related suffering and disability. Pain 131 (2007) 63-69

McCracken LM, Yang S. (2006) The role of values in a contextual cognitive-behavioral approach to chronic pain. Pain 123 (2006) 137-145

McCracken LM, Vowels KE, Eccleston C. (2004). Acceptance of chronic pain: component analysis and a revised assessment method. Pain 2004;107:159-66.

McElhone K, Abbott J, Shelmerdine J, Bruce IN, Ahmad Y, Gordon C. (2007). Development and validation of a disease-specific healthy-related quality of life measure, the LupusQOL, for adults with systemic lupus erythematosus. Arthritis Rheum 2007; 57(6):972-9.

McElhone K, Abbott J, Teh LS. (2006). A review of health related quality of life in systemic lupus erythematosus. Lupus 2006; 15: 633-643.

Michalski JP \& Kodner C. (2010) Systemic lupus erythematosus: safe and effective management in primary care. rim Care. (Dec 2010) 37(4):767-78, vii.

Moses N, Wiggers J, Nicholas C, Cockburn J. (2007). Development and psychometric analysis of the systemic lupus erythematosus questionnaire (SLENQ). Qual Life Res 2007; 16(3):461-6.

Nakashima CA, Galhardo AP, Silva JF, Fiorenzano GR, Santos AB Leite MF, Nogueira MA, Menolli PV, Menolli RA. (2011). Incidence and clinical-laboratory aspects of systemic lupus erythematosus in a Southern brazilian city. Rev Bras Reumatol. 2011 Jun;51(3):235-239.

National Collaborating Centre for Mental Health. National Institute for Health and Clinical Excellence [NICE] (2009) Depression in adults with a chronic physical health problem. Treatment and management. www.nice.org.uk/CG91 
Ng P. \& Chan W. (2007). Group psychosocial program for enhancing psychological wellbeing of people with systemic lupus erythematosus. J Soc Work Disabil Rehabil. 2007;6(3):75-87.

N Navarrete-Navarrete, MI Peralta-Ramírez, JM Sabio, I Martínez-Egea, A Santos-Ruiz, J Jiménez-Alonso. (2010). Quality-of-life predictor factors in patients with SLE and their modification after cognitive behavioural therapy. Lupus 19, 1632-1639.

Niller HH, Wolf H Ay E, Minarovits J. (2011). Minarovits J Epigenetic dysregulation of epstein-barr virus latency and development of autoimmune disease. Adv Exp Med Biol. 2011;711:82-102.

Neill J. (2005) Exploring underlying life patterns of women with multiple sclerosis or rheumatoid arthritis: comparison with NANDA dimensions. Nursing Science Quarterly 18(4), 344-352.

Neill J . , Belan I . \& Ried K. (2006) Effectiveness of non-pharmacological interventions for fatigue in adults with multiple sclerosis, rheumatoid arthritis, or systemic lupus erythematosus: a systematic review. Journal of Advanced Nursing 56(6),617-635

Nowicka-Sauer K. (2007). Patients' perspective: lupus in patients' drawings. Assessing drawing as a diagnostic and therapeutic method. Clin Rheumatol. 2007 Sep;26(9):1523-5. Epub 2007 Apr 20

Nowicka-Sauer K, Czuszynska Z, Smolenska Z, Siebert J (2011) Neuropsychological assessment in systemic lupus erythematosus patients: clinical Clin Exp Rheumatol. Mar-Apr;29(2):299-306. Epub 2011 Apr 19.

Obermoser G, Zelger B. (2008). Triple need for photoprotection in lupus erythematosus. Lupus 17:525-7.

Panopalis P, Julian L, Yazdany J. (2007). Impact of memory impairment on employment status in persons with systemic lupus erythematosus. Arthritis Rheum; 57 : 1453 60.

Ramírez R. (2007). Depresión, primera manifestación de Lupus Eritematoso Sistémico. Semergen 2007; 33:438-40. Vol.33, No. 8.

Robles-Ortega H, Peralta-Ramírez MI. (2006). Programa para el control del estrés, (ed). Pirámide; 2006.

Roelofs J, McCracken L, Peters ML, Crombez G, van Breukelen G. (2004). Vlaeyen JWS. Psychometric evaluation of the Pain Anxiety Symptoms Scale (PASS) in chronic pain patients. J Behav Med 2004;27:167-83.

Sanchez ML, McGwin G Jr, Durán S, Fernández M, Reveille JD, Vilá LM, Alarcón GS. (2009). Factors predictive of overall health over the course of the disease in patients with systemic lupus erythematosus from the LUMINA cohort (LXII): use of the SF-6D. Clin Exp Rheumatol.2009 Jan-Feb;27(1):67-71.

Sheldon, B. (1995) Cognitive-Behavioural Therapy. Research, practice and philosophy. Routledge, London.

Stricker C.T., Drake D., Hoyer K.A. \& Mock V. (2004) Evidencebased practice for fatigue management in adults with cancer: exercise as an intervention. Oncology Nursing Forum 31(5), 963-974.

Taylor JK. \& McMurray RV. (2011). Medical therapy for systemic lupus erythematosus. J Miss State Med Assoc..2011 Feb;52(2):39-43. 
Thumboo J, Strand V. (2007) Health-related Quality of Life in Patients with Systemic Lupus Erythematosus: An Update. Ann Acad Med Singapore February 2007;36 (2):115-22

Villanueva T. (2009). Family Medicine, the specialty of the future: the Portuguese situation within the European context. International Archives of Medicine 2009, 2:36

Vogel A, Bhattacharya S, Larsen JL \& Jacobsen S (2011). Do subjective cognitive complaints correlate with cognitive impairment in systemic lupus erythematosus? A Danish outpatient study. Lupus (2011) 20, 35-43

WHOQOL Group. The World Health Organization quality of life assessment (WHOQOL): position paper from the World Health organization. Soc Sci Med 1995; 41: 14031409.

Wagner L.I. \& Cella D. (2004) Fatigue and cancer: causes, prevalence and treatment approaches. British Journal of Cancer 91(5), 822-828.

Watson T. \& Mock V. (2004) Exercise as an intervention for cancerrelated fatigue. Physical Therapy 84(8), 736-743.

Yildirim-Toruner C. \& Diamond B. (2011). Current and novel therapeutics in the treatment of systemic lupus erythematosus. J Allergy Clin Immunol February 2011, Vol. 127, No. 2

Zakeri Z, Shakiba M, Narouie B, Mladkova N, Ghasemi-Rad M, Khosravi A. (2011). Prevalence of depression and depressive symptoms in patients with systemic lupus erythematosus: Iranian experience. Rheumatol Int.2011 Jan 21.

Zifko U. (2004) Management of fatigue in patients with multiple sclerosis. Drugs 64(12), 1295-1304. 


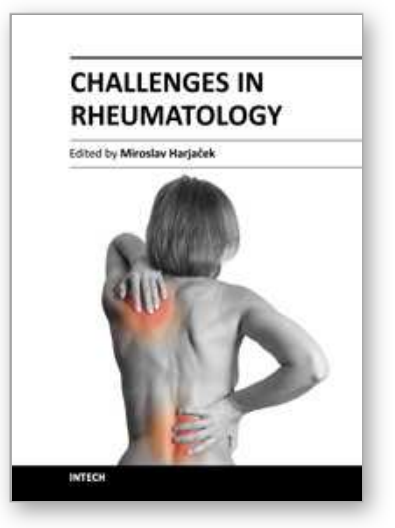

\author{
Challenges in Rheumatology \\ Edited by Dr. Miroslav Harjacek
}

ISBN 978-953-307-848-9

Hard cover, 190 pages

Publisher InTech

Published online 22, December, 2011

Published in print edition December, 2011

Rheumatology is a subspecialty of medicine that focuses on the biology, cause, diagnosis and the treatment of a variety of musculoskeletal and other systemic diseases. The field of rheumatology is expanding rapidly and several very exciting developments have occurred during the recent years. Firstly, there has been a new dramatic understanding of the nature of inflammation and the possibility of specifically regulating the aberrant immune inflammatory response. Secondly, an understanding of pathogenesis has lead to the development of new, more targeted therapies. Challenges in Rheumatology has assembled an impressive group of international experts who have studied specific aspects of certain rheumatic diseases and have extensive experience either in pathophysiology, or with the in-depth diagnosis and/or management of rheumatic patients. They communicate their knowledge and experience to the reader in chapters that are conveniently organized as pathophysiology, clinical manifestations and diagnosis of selected rheumatic diseases, medical and perioperative orthopedic management, and the economic impact of rheumatic diseases. We hope that this book will help trainees become better physicians and scientists, and that it will help practicing rheumatologists to provide better care, and ultimately, improve the quality of life of our patients.

\title{
How to reference
}

In order to correctly reference this scholarly work, feel free to copy and paste the following:

Raquel Ramîrez Parrondo (2011). Integral Treatment of Systemic Lupus Erythematosus, Challenges in Rheumatology, Dr. Miroslav Harjacek (Ed.), ISBN: 978-953-307-848-9, InTech, Available from: http://www.intechopen.com/books/challenges-in-rheumatology/integral-treatment-of-systemic-lupuserythematosus

\section{INTECH}

open science | open minds

\section{InTech Europe}

University Campus STeP Ri

Slavka Krautzeka 83/A

51000 Rijeka, Croatia

Phone: +385 (51) 770447

Fax: +385 (51) 686166

www.intechopen.com

\section{InTech China}

Unit 405, Office Block, Hotel Equatorial Shanghai

No.65, Yan An Road (West), Shanghai, 200040, China

中国上海市延安西路65号上海国际贵都大饭店办公楼405单元

Phone: +86-21-62489820

Fax: +86-21-62489821 
(C) 2011 The Author(s). Licensee IntechOpen. This is an open access article distributed under the terms of the Creative Commons Attribution 3.0 License, which permits unrestricted use, distribution, and reproduction in any medium, provided the original work is properly cited. 